\title{
A EUTANÁSIA SOB A ÉGIDE DA AUTONOMIA DA VONTADE E DA PERSPECTIVA FAMILIAR
}

\author{
EUTHANASIA UNDER THE AEGIS OF THE AUTONOMY OF THE WILL \\ AND FAMILY PERSPECTIVE
}

Manoela Souza Silva ${ }^{1}$

\begin{abstract}
RESUMO
O direito à vida entendido à luz da dignidade da pessoa humana é um direito fundamental e um dos bens mais preciosos do ser humano. Quando esse direito fundamental colide com a terminalidade da vida é necessário questionar o objeto por meio da bioética e, após, a interpretação desta, usar o biodireito como forma de decidir o conflito bioético. Tendo-se em vista que a maior pauta dessa questão seria a autonomia da vontade, que é a pedra basilar da bioética, há uma necessidade de indagar sob o amparo da zetética, o quão autodeterminado e autônomo nas suas vontades é considerado o ser humano para decidir o momento de sua própria morte. Outrossim, diante de várias colisões dentro do tema da eutanásia, deparamo-nos com o embate que há entre o direito de autodeterminação do ser humano, o direito de família e a fé cristã. Este artigo tem o intuito de analisar a morte assistida e as maiores problematizações sobre o tema.
\end{abstract}

Palavras-chaves: biodireito, bioética, eutanásia.

\begin{abstract}
The right to life understood in the light of the dignity of the human person is a fundamental right and one of the most precious assets of the human being. When this fundamental right collides with the terminality of life, it is necessary to question the object through bioethics and, after its interpretation, to use the bio-law as a way to decide the bioethical conflict. Assuming that the major issue of this question would be the autonomy of the will, which is the cornerstone of bioethics, there is a need to inquire under the protection of zetetics, how self-determined and autonomous of his will is considered the human being to decide the moment of his own death. Moreover, up of various collisions on the subject of euthanasia, we face the clash between the right of self-determination, the right to family and the Christian faith. This article aims to analyze assisted death and the major problematizations on this subject.
\end{abstract}

Keywords: biolaw, bioethics, euthanasia.

\section{INTRODUÇÃO}

Diante dos avanços tecnológicos, percebe-se um progresso dos métodos medicinais e uma maior atenção à Biotecnologia, esta, por sua vez, tendo a intenção de viabilizar melhorias à

1 Graduanda da Faculdade Nacional de Direito da Universidade Federal do Rio de Janeiro. manoelasouzasilva@outlook.com 
saúde das pessoas que constituem uma determinada sociedade. Ademais, reconhecemos que as mudanças tecnológicas são importantes instrumentos de informação. O Direito, sendo um fenômeno cultural e indispensável à sociedade civil para que haja tutela e garantias dos direitos dos cidadãos, deve não apenas funcionar por meio da zetética, mas, também, acompanhar os avanços tecnológicos, que vai permitir uma melhor análise dos fatos e não apenas a mera suposição de causalidades espúrias. Sendo assim, a tecnologia traz uma melhor legitimidade para a análise dos fatos.

Outrossim, muito questiona-se sobre de que forma o avanço da tecnologia ajudaria ou melhoraria a saúde de indivíduos de uma sociedade do século XXI quando o Direito se encontra com a Bioética, dando resultado, desta forma, ao Biodireito. Aludindo Fátima Oliveira²

É necessário que se desperte na sociedade atual uma consciência bioética, garantidora de sua verdadeira autonomia. O avanço cientifico, quando planejado e discutido democraticamente na sociedade, quanto tem seus objetivos e suas consequências esclarecidos, quando é avaliada a supremacia dos seus benefícios sobre os riscos e custos, tem significado ético aceitável e é condizente com o avanço da cidadania.

Ademais, a Bioética carrega um caráter de zetética, devido aos questionamentos, tanto sociais, antropológicos, filosóficos e históricos quanto psicológicos e políticos, que o ser humano começa a fazer quando se depara com a possibilidade de sua interferência na natureza através dos avanços tecnológicos já abordados. Um desses questionamentos é a prática da eutanásia. Conforme GARRAFA, 2000:

Para a Bioética, o que é "bem" para uma comunidade moral não necessariamente significa "bem" para outra, já que suas moralidades podem ser diversas. Nesse sentido, se a ética profissional tem sua trajetória pautada em proibições, vetos, limitações ou simplesmente normatizações, a Bioética não tem por base a negativa. Ao contrário, sendo de orientação histórica laica e não religiosa ou canônica, como muitos pensam e confundem, trata de atuar afirmativamente, positivamente. Para a Bioética, a essência é a liberdade, mas com compromisso e responsabilidade.

A eutanásia é um fenômeno social que ocorre na humanidade desde seus primórdios. No entanto, foi no século XIV, na mais conhecida obra de Thomas More, Utopia, que pela primeira vez se falou nesse fato. Escreveu More:

Se a doença é incurável e faz-se acompanhar de dores agudas e contínuas angústias, os sacerdotes e magistrados devem ser os primeiros a exortar os infelizes a decidiremse a morrer. Então, devem fazer com que vejam que, não tendo mais utilidade neste mundo, não têm razão para prolongar uma vida que corre por sua conta e os torna insuportáveis para os outros.

Sendo assim, More defendeu que para viver em uma sociedade perfeita, ou seja, utópica, deveria haver a permissão da eutanásia pelo Estado. Para ele, essa era uma das características de uma sociedade utópica.

2 OLIVEIRA, F. Engenharia genética: o sétimo dia da criação. ed. 3. São Paulo: Moderna, 1996. 
No século seguinte, o termo "eutanásia" foi adotado pela primeira vez pelo filósofo e médico inglês Francis Bacon. Etimologicamente, eutanásia significa "morte boa, certa", sendo uma palavra de origem grega; eu significa "bom" ou "certo", e thanatos significa "morte", resultando, assim, em “morte boa" ou "morte certa.".

Em sua obra Historia vitae et mortis de 1623, Bacon estabeleceu que "o médico deve acalmar os sofrimentos e as dores, não apenas quando este alívio possa trazer a cura, mas também quando pode servir para procurar uma morte doce e tranquila". Desta forma, Bacon designa o dever de compaixão e empatia com aquele que está padecendo. O encontro da zetética de Bacon com o Direito resulta na ideia -constitutiva do Biodireito- de direito à morte digna, ideia, esta, não tutelada ou garantida pelo Estado brasileiro, mas que deve ser estudada e avaliada, de modo a pensar a autonomia da vontade de cada indivíduo.

Contrapondo os argumentos de More e Bacon, há a moralidade kantiana. O filósofo alemão Immanuel Kant determinou:

Se, para escapar a uma situação penosa, se destrói a si mesmo, serve-se ele de uma pessoa como de um simples meio para conservar até o fim da vida situação suportável. Mas o homem não é uma coisa; não é um objeto que pode ser utilizado simplesmente como um meio, mas pelo contrário deve ser considerado sempre e em todas as suas ações como um fim em si mesmo. Portanto não posso dispor do homem na minha pessoa para o mutilar, ou degradar ou o matar.

A eutanásia tem mais duas vertentes: ortotanásia e distanásia.

\section{ORTOTANÁSIA E DISTANÁSIA}

Entende-se, então, que a eutanásia é uma morte assistida planejada com o intuito de cessar os sofrimentos e dores, presentes ou futuros, que um ânimo sente. Além disso, é um meio de evitar que uma vida, que consegue sobreviver apenas por vias artificiais, como uso de aparelhos e remédios, continue perpetuando-se. Segundo Maria Helena Diniz ${ }^{3}$, "trata-se do prolongamento exagerado da morte de um paciente terminal ou tratamento inútil. Não visa prolongar a vida, mas sim o processo de morte".

A eutanásia pode ser classificada em três tipos:

\begin{tabular}{|c|c|c|}
\hline Voluntária & Involuntária & Não-voluntária \\
\hline Quando a morte do paciente, por & Quando há uma provocação da & Quando a morte do paciente é \\
meio de medicamentos ou pela & morte do paciente, por meio de & provocada, sem que o dito-cujo se \\
realização de procedimentos & procedimentos médicos ou & manifestasse em relação à ela. \\
\hline
\end{tabular}

3 DINIZ, M. H. O estado atual do biodireito. São Paulo: Saraiva, 2001. 


\begin{tabular}{|c|c|c|}
\hline médicos, for provocada após a & medicamentos, com ausência, & \\
anuência do paciente ou após a & porém, de anuência. & \\
consideração da sua vontade. & & \\
\hline
\end{tabular}

Quadro 1. Classificação dos tipos de eutanásia.

Fonte: A autora, 2019.

Esta classificação objetiva proposta por Neukamp F. Zum em Problem der Euthanasie ${ }^{4}$ por volta de 1937, tem o intuito de viabilizar a responsabilidade do agente, ou seja, do médico; agente, porque ele quem vai executar a ação de provocar a morte do paciente.

No entanto, há mais duas vertentes que dizem respeito à abordagem médica em relação à morte do paciente, são elas: distanásia e ortotanásia.

A prática da distanásia tem o intuito de prolongar a vida de um paciente incurável por meio da Biotecnologia na medicina, portanto, legitimando as dores e sofrimentos do enfermo. Para que se distancie essa prática dos avanços tecnológicos, é crucial a conscientização de que a morte é uma certeza inegável da condição humana. Como em Montaigne", "morrer é a própria condição de vossa condição; a morte é a parte integrante de vós mesmos" (Montaigne, 2000); cedo ou tarde, a morte acontecerá, não importa onde ou quando, um dia ela virá, e aceitá-la é aceitar também a nossa constituição mortal humana.

Na distanásia, expressão proposta pela primeira vez por Morcache no seu livro Naissance et mort, em 1904, não há um direito à morte digna, pois, esta, requer uma morte humanizada, sem a extensão de uma vida que só existe por vias artificiais e que está padecendo. Prolongar a vida de um paciente que se encontra nesses estados físico e psicológico é, também, prolongar suas dores e seus sofrimentos. $\mathrm{O}$ direito à morte digna requer compaixão e empatia, portanto, optar pelo prolongamento da vida de um enfermo em padecimento é uma conduta individualista e egoísta, tomada para ressarcir suas próprias vontades e necessidades. Muitas vezes, a distanásia, praticada no campo da saúde, é uma vontade familiar, porque perder aquele ente querido para a morte parece uma conduta intolerável e, portanto, reversível. Ademais, é um equívoco dizer que há demasiado sentimento em perspectiva familiar para que os parentes tomem a decisão de praticar a distanásia ou convençam o paciente a optar por ela, e que se deve agir com razão diante dessa contingência. Na verdade, pois, o que falta são sentimentos de compaixão e sensibilidade, como detalhou Milan Kundera ${ }^{6}$ em sua obra "A insustentável Leveza do Ser", “a compaixão, designa, portanto, a mais alta capacidade de imaginação afetiva

\footnotetext{
NEUKAMP, F. Zum. Problem der Euthanasie. Der Gerichtssaal, 109:403, 1937.

MONTAIGNE, M. De como filosofar é aprender a morrer. vol. 1. São Paulo: Abril Cultural, 2000.

6 KUNDERA, M. A insustentável leveza do ser. ed. 39. Rio de Janeiro: Nova Fronteira, 1985, p.26.
} 
- a arte da telepatia das emoções. Na hierarquia dos sentimentos, é o sentimento supremo". Contudo, como dispõe Pessini ${ }^{7}$, o termo distanásia propõe um martírio prolongado que ocasiona uma morte com sofrimento físico ou psicológico do enfermo lúcido. Outrossim, o termo caracteriza a forma de fazer a vida do indivíduo durar por mais tempo de modo artificial, sem perspectiva de cura ou melhora.

A ortotanásia tem como sua principal característica a morte natural, este é o seu intuito maior e único. Nesta vertente, não há a programação da morte do paciente com o objetivo de cessar uma existência que se dá por via de remédios e aparelhos, como acontece na eutanásia. Outrossim, não há a submissão do paciente a um tratamento penoso que possua o objetivo de prolongar a sua vida, como há na distanásia. Na ortotanásia, há a suspensão de medicamentos e de procedimentos invasivos que pretendem estender a vida do paciente, fazendo uso apenas dos que visam a amenização das dores sentidas pelo dito-cujo. Assim como bem menciona Tereza Rodrigues Vieira ${ }^{8}$, “desta forma, diante de dores intensas sofridas pelo paciente terminal, consideradas por este como intoleráveis e inúteis, o médico deve agir para amenizálas, mesmo que a consequência venha a ser, indiretamente, a morte do paciente". Sendo assim, a ortotanásia é o ato de morrer naturalmente.

Ademais, a ortotanásia estará envolta de cuidados paliativos, para que o paciente tenha qualidade de vida e possa exercer sua autonomia da vontade, como escolher onde morrer, as medidas para aliviar suas dores; é uma garantia de que o paciente possa determinar por meio de sua autonomia como serão os seus últimos dias de vida e por qual tratamento quer passá-los.

\section{LEGISLAÇÃO}

A prática da eutanásia é legalizada em alguns países, como os países europeus Holanda, Bélgica, Suíça, Luxemburgo, Inglaterra, o norte-americano Canadá e Estados-Unidos (apenas em cinco Estados) e o latino-americano Colômbia.

A Holanda foi o primeiro país a legalizar a eutanásia, que vinha sendo debatida nos países baixos desde 1970. Assim como foi debatido na Inglaterra, também no século XX, a possibilidade de uma legislação para a morte assistida, proposta em 1931 por Millard, porém rejeitada pela Câmara dos Lordes. No entanto, essa proposta desencadeou vários debates sobre a eutanásia e originou a criação da Voluntary Euthanasia Society, em 1935, hoje conhecida como Dignity In Dying, devido às alterações no nome, mas que permanece ativa até hoje.

8 VIEIRA, T. R. Bioética e direito. São Paulo: Jurídica Brasileira, 1999, p. 90. 
Outrossim, a proposta de Millard também serviu como base, anos depois, para os Países Baixos, da mesma forma como a doutrina do penalista espanhol Jiménez de Asúa serviu de base para a inclusão da eutanásia como "homicídio piedoso" no Código Penal Uruguaio em 1934. Asúa9 definiu a eutanásia como a "morte que alguém proporciona a uma pessoa que padece de uma enfermidade incurável ou muito penosa, e a que tende a extinguir a agonia demasiado cruel ou prolongada".

Em 2001, foi aprovada uma legislação sobre morte assistida na Holanda, que entrou em vigor em 2002 como "Lei sobre a cessação da vida a pedido e o suicídio assistido", possuindo alguns requisitos como: o paciente que goza de plena consciência e controle das suas capacidades mentais, que sofre de doença incurável sem perspectiva de melhora e que esteja sofrendo dores insuportável deve fazer um pedido expresso da sua vontade.

$\mathrm{Na}$ Colômbia a primeira morte assistida foi provocada em 2015. A Bélgica legalizou a eutanásia exclusivamente para belgas que vivem na Bélgica, também, em 2002, como a Holanda. Na Suíça, a morte assistida é permitida desde a década de 1940. Portanto, com exceção da Suíça, é notável o quão recente são as legislações sobre morte assistida pelo mundo. É um fenômeno que sempre aconteceu, mas que a sua problematização tem tomando proporções maiores no final da década de 1990 e no início do século XXI.

O Brasil, por sua vez, não possui uma legislação sobre a prática da morte assistida, no entanto, mesmo não possuindo um texto explícito que trate a eutanásia na legislação brasileira, entende-se que a eutanásia estaria inclusa no artigo $121, \$ 1^{\circ}$ do Código Penal Brasileiro ${ }^{10}$ que disciplina que:

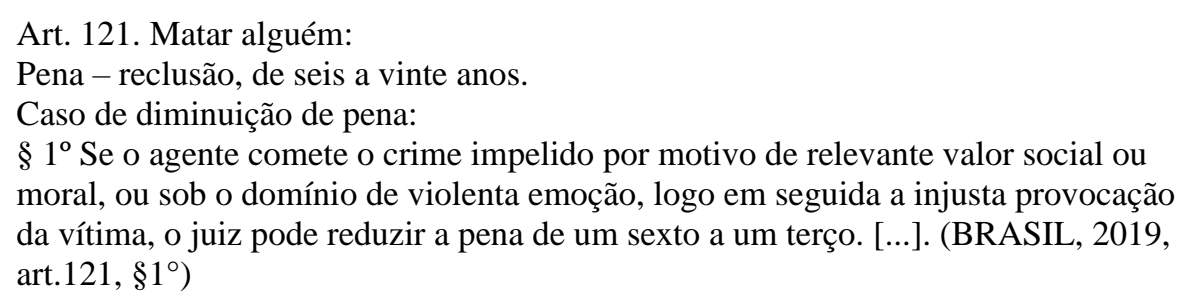

A justificativa do valor social ou moral compreende que a conduta do médico de praticar a eutanásia no paciente foi um ato de sensibilidade, no qual houve a prevalência da paixão sobre a razão. A Exposição de Motivos do Código Penal ${ }^{11}$ de Francisco Campos estabelece que valor social ou moral "é aquele que, em si mesmo, é aprovado pela moral prática como, p. ex, a

ASÚA, L. J. Liberdade de amar e direito a morrer. Belo Horizonte: Mandamentos, 2003.

BRASIL. Código Penal Brasileiro. São Paulo: Rideel, 2019.

11 Exposição de motivos da parte especial do código penal. Disponível em <http://honoriscausa.weebly.com/uploads/1/7/4/2/17427811/exmecp_parte_especial.pdf>. Acesso em 10/08/2019. 
compaixão ante o irremediável sofrimento da vítima (caso de homicídio eutanásico), a indignação contra um traidor da pátria, etc".

Ademais, há o entendimento de que a eutanásia pode ser um fato atípico ou imputada também no artigo 122 do Código Penal Brasileiro ${ }^{12}$ que dispõe que:

Art. 122 - Induzir ou instigar alguém a suicidar-se ou prestar-lhe auxílio para que o faça:

Pena - reclusão, de dois a seis anos, se o suicídio se consuma; ou reclusão, de um a três anos, se da tentativa de suicídio resulta lesão corporal de natureza grave. [...]. (BRASIL, 2019, art.122)

Outrossim, no século XXI, com a problemática da eutanásia cada vez maior e em discussão no Brasil, o Conselho Federal de Medicina se posicionou e estabeleceu parâmetros de como o médico deveria agir face à vontade do paciente em relação ao seu tratamento, disciplinando a Resolução 1.805/2006 ${ }^{13}$ :

Art. $1^{\circ}$ É permitido ao médico limitar ou suspender procedimentos e tratamentos que prolonguem a vida do doente em fase terminal, de enfermidade grave e incurável, respeitada a vontade da pessoa ou seu representante legal.

$\S 1^{\circ} \mathrm{O}$ médico tem a obrigação de esclarecer ao doente ou a seu representante legal as modalidades terapêuticas adequadas em casa situação.

$\S 2^{\circ}$ A decisão referida no caput deve ser fundamentada e registrada no prontuário.

$\S 3^{\circ}$ É assegurado ao doente ou a seu representante legal o direito de solicitar segunda opinião médica.

Art. $2^{\circ} \mathrm{O}$ doente continuará a receber todos os cuidados necessários para aliviar os sintomas que levam ao sofrimento, assegurada a assistência integral, o conforto físico, psíquico, social e espiritual, inclusive assegurando-lhe o direito de alta hospitalar. (BRASIL, CFM 1805/06)

É notável que a Resolução 1.805/06 guia as condutas do médico em relação ao seu paciente em questões de ortotanásia, ou seja, de morte natural, uma vez que permite ao médico a suspensão de tratamentos que prolonguem a vida do enfermo que não tem perspectiva de melhora. Porém, posteriormente, na Resolução 1.995/2012, reconhece-se a legitimação da autonomia do paciente em conjunto do seu médico, dando a possibilidade de o enfermo recusar a prática da distanásia no seu tratamento, ou seja, do paciente escolher não prosseguir com a utilização de vias artificiais para prolongar sua vida. Portanto, a Resolução 1.995/12 estabelece que:

Art. $1^{\circ}$ Definir diretivas antecipadas de vontade como o conjunto de desejos, prévia e expressamente manifestados pelo paciente, sobre cuidados e tratamentos que quer, ou não, receber no momento em que estiver incapacitado de expressar, livre e autonomamente, sua vontade.

Art. $2^{\circ}$ Nas decisões sobre cuidados e tratamentos de pacientes que se encontram incapazes de comunicar-se, ou de expressar de maneira livre e independente suas vontades, o médico levará em consideração suas diretivas antecipadas de vontade.

$\S 1^{\circ}$ Caso o paciente tenha designado um representante para tal fim, suas informações

12 BRASIL. Código Penal Brasileiro. Op., cit.

13 . Conselho Federal de Medicina. Resolução CFM N No 1.805/2006. Disponível em <http://www.portalmedico.org.br/resolucoes/cfm/2006/1805_2006.htm>. Acesso em 03/07/2019. 
serão levadas em consideração pelo médico.

$\S 2^{\circ} \mathrm{O}$ médico deixará de levar em consideração as diretivas antecipadas de vontade do paciente ou representante que, em sua análise, estiverem em desacordo com os preceitos ditados pelo Código de Ética Médica.

$\S 3^{\circ}$ As diretivas antecipadas do paciente prevalecerão sobre qualquer outro parecer não médico, inclusive sobre os desejos dos familiares.

$\S 4^{\circ} \mathrm{O}$ médico registrará, no prontuário, as diretivas antecipadas de vontade que lhes foram diretamente comunicadas pelo paciente.

$\S 5^{\circ}$ Não sendo conhecidas as diretivas antecipadas de vontade do paciente, nem havendo representante designado, familiares disponíveis ou falta de consenso entre estes, o médico recorrerá ao Comitê de Bioética da instituição, caso exista, ou, na falta deste, à Comissão de Ética Médica do hospital ou ao Conselho Regional e Federal de Medicina para fundamentar sua decisão sobre conflitos éticos, quando entender esta medida necessária e conveniente.

Contudo, é necessário pensar no fato da legislação brasileira não possuir um texto que trate sobre a morte assistida. A problemática é a ausência do Princípio da Legalidade. O artigo $5^{\circ}$ da Constituição, em seu inciso segundo, afirma que "ninguém será obrigado a fazer ou deixar de fazer alguma coisa senão em virtude de lei”, desta forma, o princípio da legalidade garante que as pessoas são livres, porém, sob a égide das leis, tendo que possuir condutas de acordo com elas. Portanto, ao relacionar o princípio da legalidade com a prática da eutanásia é fundamental questionar se há realmente crime e pena para algo que não tem lei, afinal, "nullum crimen, nulla poena, sine lege".

\section{AUTONOMIA DA VONTADE}

A Constituição Brasileira de 1988 reconhece a dignidade humana como princípio fundamental, prevista no artigo $1^{\circ}$, inciso III da Carta Magna; correspondendo a um direito fundamental que infunde deferência e garante ao indivíduo o respeito deste como ser humano, tutelando os seus direitos e a sua honra. Equitativamente, manifestou-se o Supremo Tribunal Federal $^{14}$ :

(...) o postulado da dignidade da pessoa humana, que representa - considerada a centralidade desse princípio essencial $\left(\mathrm{CF}\right.$, art. $1^{\circ}$, III) - significativo vetor interpretativo, verdadeiro valor-fonte que conforma e inspira todo o ordenamento constitucional vigente em nosso País e que traduz, de modo expressivo, um dos fundamentos em que se assenta, entre nós, a ordem republicana e democrática consagrada pelo sistema de direito constitucional positivo (...).

Por conseguinte, é conferido à dignidade da pessoa humana um status de princípio fundamental e essencial, e é à luz do princípio da dignidade da pessoa humana que se reconhece o direito à vida, prevista no art. $5^{\circ}$, caput da Constituição Federal Brasileira. No entanto, se há um direito à vida, que está intrinsecamente ligada à autonomia, e zela-se pela vida do indivíduo

14 HC 95464, Relator(a): Min. CELSO DE MELLO, Segunda Turma, julgado em 03/02/2009, DJe-048 DIVULG 12-03-2009 PUBLIC 13-03-2009 EMENT VOL-02352-03 PP-00466. 
para que ela seja digna, deve também haver um direito à morte digna que garanta à pessoa um óbito sem padecimento.

$\mathrm{O}$ direito à morte digna seria reconhecido sob a égide da autonomia da vontade, que é um dos maiores valores de um ser humano que está inserido em um contexto de dignidade de sua pessoa humana. A liberdade, como traço essencial, de poder optar por uma morte sem dores e sofrimentos é um ato de autonomia. De acordo com Kant ${ }^{15}$ :

A autonomia é aquela sua propriedade graças à qual ela é para si mesma a sua lei (independentemente da natureza dos objetos do querer). O princípio da autonomia é, portanto, não escolher senão de modo que as máximas da escolha estejam incluídas, simultaneamente, no querer mesmo, como lei universal.

A problemática maior consiste em como ter autonomia se o Direito impõe ao indivíduo leis que devem ser cumpridas e atos que devem ser tomados apenas se não forem proibidos em lei, como é amparado no princípio da legalidade. Diante disso, torna-se quase impossível tomar decisões se há uma ameaça coercitiva por parte do Estado que impele uma série de sanções em consequência do descumprimento das regras do ordenamento jurídico. No entanto, reconhecese que o Direito, conforme o filósofo mineiro Joaquim Carlos Salgado ${ }^{16}$, "deve trazer em si o conceito de liberdade e de igualdade, que são elementos constitutivos da ideia de justiça". Logo, o Direito não apenas existe como manifestação da igualdade, mas, também, da liberdade, porque não se pode interpretar as sanções apenas como ameaças à moral do homem, uma vez que elas são formas de manter a liberdade do outro intacta, de modo que nenhum indivíduo possa interferir na sua autonomia e, da mesma forma, você também não possa fazer qualquer tipo de interferência na autonomia de outrem. Nesse contexto, manifestou-se Kant ${ }^{17}$ :

\begin{abstract}
A resistência que frustra o impedimento de um efeito promove este efeito e é conforme ele. Ora, tudo que é injusto é um obstáculo à liberdade de acordo com leis universais. Mas a coerção é um obstáculo ou resistência à liberdade. Consequentemente, se um certo uso da liberdade é ele próprio um obstáculo à liberdade de acordo com leis universais (isto é, é injusto), a coerção que a isso se opões (como um impedimento de um obstáculo à liberdade) é conforme à liberdade de acordo com leis universais (isto é, é justa). Portanto, ligada ao direito pelo princípio de contradição há competência de exercer coerção sobre alguém que o viola.
\end{abstract}

Isto posto, Kant estabeleceu que a coerção usada pelo Estado para garantir que a população haja de acordo com o ordenamento jurídico é justa, porque condutas demasiada livres podem afetar a liberdade do próximo e, desse modo, afetá-lo nas suas esferas sociais. Porém, a morte assistida à luz do direito à morte digna não afetaria nenhuma esfera de autodeterminação individual, além do próprio assistido, uma vez que seria uma escolha feita por ele para ser

15 KANT, I. Fundamentação da metafísica dos costumes. In: Textos selecionados. São Paulo: Abril, 1994.

16 SALGADO, J. C. A idéia de justiça em Kant: seu fundamento na liberdade e na igualdade. Belo Horizonte: UFMG, 1986.

17 KANT, I. A metafísica dos costumes. São Paulo: EDIPRO, 2003. 
provocada nele mesmo. É neste contexto que o jurista argentino Carlos Santiago Nino ${ }^{18}$ afirma que autonomia é "a liberdade de realizar qualquer conduta que não prejudique a terceiros". Dessa forma, o entendimento que visualizamos é que não há o porquê de uma sanção para algo que não se esquiva da esfera de autodeterminação individual do paciente que opta pela eutanásia, já que a liberdade dele não fere a liberdade de outrem, ou seja, ela não se comporta de forma injusta com a liberdade de outro indivíduo. Conforme o professor e penalista Luís Greco $^{19}$ :

Um comportamento só pertence à esfera de autonomia se a sua prática por um indivíduo não exclui que outros também o pratiquem. Ou seja, a autonomia de um indivíduo não pode colidir com a de outro, pois senão uma autonomia prevaleceria às custas da outra - a autonomia de um valeria mais que a do outro - e se teria um privilégio.

Logo, não deve haver uma hierarquia de autonomias entre os indivíduos. Nos apetece uma sociedade plural, que possui mais facilidade de acontecer à luz da autonomia da vontade de cada indivíduo dessa sociedade, conforme o filósofo alemão Jürgen Habermas ${ }^{20}$ afirma "a inclusão do outro significa que as fronteiras da comunidade estão abertas a todos - também e justamente àqueles que são estranhos um ao outro - e querem continuar sendo estranhos". A inclusão de um direito à morte digna ao ordenamento jurídico além de uma forma de legitimar a autonomia da vontade do homem, é, também, uma forma plural -se pensada além da diversidade de características dos indivíduos, mas na multiplicidade de vontades- de se pensar a sociedade, já que um direito seria concedido àquelas pessoas que querem poder exercer sua autonomia da vontade optando pela sua morte assistida em face de todos os sofrimentos que a permeia física e psicologicamente. Neste mesmo sentindo, afirmou Reis ${ }^{21}$ :

É ter autonomia para decidir sobre o seu tratamento e sobre a sua vida, é não ter a sua vontade ignorada mesmo quando a voz da sua consciência tornou-se inaudível; significa não ser abandonado pelo médico quando este resolve que não há mais nada a fazer, não ter seu tratamento prolongado infinitamente. Uma "boa morte" conduz ao direito de amparo físico e espiritual nos momentos finais. Morrer com dignidade é dar ao paciente incurável a autorização para morrer com nobreza e integridade.

Por conseguinte, o direito à morte digna é um ato que seria previsto visando não apenas sentimentos de compaixão e empatia, mas dando legitimidade à vontade do paciente e à moral deste, que é pertencente à autonomia da vontade. No entanto, nosso modo de ver não pode prevalecer sobre os outros em uma sociedade democrática, mas é necessário que haja uma

18 NINO, C. S. Ética y derechos humanos: un ensayo de fundamentación. Buenos Aires: Editorial Astrea de Alfredo y Ricardo DePalma, 2007.

19 GRECO, L. Posse de drogas, privacidade, autonomia: reflexões a partir da decisão do Tribunal Constitucional argentino sobre a inconstitucionalidade do tipo penal de posse de drogas com a finalidade de próprio consumo. Revista Brasileira de Ciências Criminais. São Paulo, v. XVIII, n. 87, nov./dez. 2010.

20 HABERMAS, J. A inclusão do outro. São Paulo: Loyola, 2002.

21 REIS, M. M. Teoria dos direitos fundamentais. $2^{\text {a }}$ ed. Rio de Janeiro: Renovar, 2009. 
análise do quanto a possibilidade de morte assistida no Brasil possa afetar terceiros, e pelo o que foi analisado neste tópico, não há possibilidade da morte assistida de um enfermo, optada sob a égide da autonomia da vontade, interferir na esfera de autodeterminação individual de outrem. Se a tutela da autonomia se encontra no direito à vida, é certo que ela deve poder se encontrar também no direito à morte digna. Ademais, de acordo com o Ministro Luís Roberto Barroso e Letícia de Campos Velho Martel $^{22}$, há um predomínio da dignidade da pessoa humana prevista na Carta Magna com sentido de autonomia, principalmente porque a Constituição de 1988 nasceu logo após o fim da ditadura militar brasileira, fase em que os indivíduos não podiam exercer livremente sua autonomia individual, e deu início ao Estado Democrático de Direito no Brasil. Portanto, da mesma forma que a moralidade kantiana afirma o Direito como uma expressão não apenas de igualdade, mas também de liberdade, a Constituição de 1988 estrutura-se em autonomia e liberdade individual. Conhecida como Constituição Cidadã, esta propõe um ordenamento jurídico plural com a intenção de promover uma existência humana digna, e essa promoção se faz à luz da autonomia da vontade de cada indivíduo.

Para mais, em um contexto filosófico, Jean-Paul Sartre também elaborou conceitos morais, sendo um deles a autonomia. Sartre ${ }^{23}$ afirma que a liberdade é, intrinsecamente, ação e autonomia de escolha. O filósofo francês denomina como "projeto original" toda escolha que uma pessoa faz, a partir da autonomia individual, sobre ela mesma. A autonomia de escolha do paciente concedida pelo direito à morte digna seria o último ato de humanismo existencialista que uma pessoa poderia ter; a possibilidade de nos seus últimos dias, meses ou anos de vida, poder exercer um projeto original, ou seja, fazer uma escolha sobre si própria.

\section{EUTANÁSIA E A FÉ CRISTÃ ${ }^{24}$}

A eutanásia apesar de ser um fenômeno social antigo e praticada, durante a história, por muitas civilizações antigas, ainda é um assunto tabu, principalmente na perspectiva da maioria das igrejas do século XXI. Para as igrejas, a eutanásia pode ser tanto considerada pelo cristianismo como pode ser inconciliável com a fé cristã. Temas bioéticos como aborto e

22 BARROSO, L. R.; MARTEL, L. C. V. A morte como ela é: dignidade e autonomia individual no final da vida. In: GOZZO, Débora; LIGIERA, Wilson Ricardo. Bioética e Direitos Fundamentais (Orgs.). São Paulo: Saraiva, 2012

23 SARTRE, Jean-Paul. L'être et le néant: essai d'ontologie phénoménologique. France: Gallimard, 2001.

24 Para pesquisar e escrever sobre esse tópico, além dos materiais de leitura usados, conversei com duas pessoas cristãs, uma evangélica e outra católica apostólica romana, procurando entender a perspectiva das igrejas delas sobre a morte assistida. Ademais, esclareço que sempre que eu me referir à fé cristã, o cristianismo ou às igrejas, eu estarei me referido àqueles que são contrários à eutanásia - a não ser que eu especifique que não - . 
eutanásia são temas discutidos recorrentemente dentro das igrejas. No entanto, a fé cristã, assim como o direito natural, funciona de forma atemporal, ou seja, não pode ser afetada pelo passar do tempo, afinal, a bíblia, que é a palavra de Deus aos cristãos, é inalterável, sendo ela mesma um livro atemporal.

O cristianismo é uma religião altamente presente na sociedade brasileira, segundo estatísticas do Censo de 2010 feito pelo Instituto Brasileiro de Geografia e Estatística (IBGE) ${ }^{25}$, o Brasil possui uma porcentagem de $86,8 \%$ de cristãos, enquanto que no mundo, aproximadamente, 2,3 bilhões de pessoas se identificam cristãs, de acordo com dados do instituto Pew Research Center ${ }^{26}$.

Do ponto de vista moral da igreja, entende-se que a vida é dada por Deus, e só por ele deve ser retirada. A eutanásia, então, uma vez que consiste em uma morte programada para cessar dores físicas e psicológicas, estaria fora da moral cristã ensinada nas igrejas e nos livros cristãos. $\mathrm{O}$ entendimento das igrejas contrárias à morte assistida é que a vida deve prevalecer sempre, pois esta é sagrada e divina, não importando se uma pessoa está padecendo ou se não possui mais nenhuma expectativa de vida. Neste contexto, afirma o teólogo e filósofo Santo Agostinho de Hipona ${ }^{27}$ que "nenhuma pessoa deve infligir em si mesma morte voluntária, pois isso seria fugir dos sofrimentos do tempo presente para se atirar nos sofrimentos da eternidade. Nenhuma pessoa deve acabar com a própria vida a fim de obter uma vida melhor”. Logo, fugir do sofrimento atual é optar pelo sofrimento eterno. As igrejas enfrentam o sofrimento humano através da busca do milagre divino e da fé de que Deus pode curar toda dor e sofrimento e, até mesmo, através do milagre, aumentar a expectativa de vida de um indivíduo ou fazê-la melhorar de forma que a pessoa não necessite mais de assistência médica ou de seguir um tratamento. Sendo assim, as igrejas acreditam e praticam a cura física, espiritual e psicológica, através do contato com Deus e da força divina deste. A partir desse mesmo pensamento, o Papa Pio XII ${ }^{28}$, no ano de 1957, declarou em uma assembleia de clínicos, cirurgiões e anestesistas:

Toda forma de eutanásia direta, isto é, a administração de narcóticos para provocarem ou causarem a morte, é ilícita porque se pretende dispor diretamente da vida. Um dos princípios fundamentais da moral natural e cristã é que o homem não é senhor e

25 BRASIL. Instituto Brasileiro de Geografia e Estatística. Disponível em <https://www.ibge.gov.br/estatisticas/sociais/trabalho/9662-censo-demografico-

2010.html?edicao=9749\&t=destaques $>$. Acesso em 03/07/2019.

26 Christians remain world's largest religious group, but they are declining in Europe. Pew Research Center. Disponível em <https://www.pewresearch.org/fact-tank/2017/04/05/christians-remain-worlds-largestreligious-group-but-they-are-declining-in-europe/> Acesso em 03/07/2019.

27 AUGUSTINE, ST. The Early Church Fathers and Other Works. Scotland: Wm. B. Eerdmans Pub. Co., 1867.

28 Discurso del Santo Padre Pío XIII sobre las implicaciones religiosas y morales de la analgesia. Vatican. Disponível em <http://w2.vatican.va/content/pius-xii/es/speeches/1957/documents/hf_pxii_spe_19570224_anestesiologia.html>. Acesso em 03/08/2019. 
proprietário, mas apenas usufrutuário de disposição direta que visa à abreviação da vida como fim e como meio. Nas hipóteses que vou considerar, trata-se unicamente de evitar ao paciente dores insuportáveis, por exemplo, no caso de câncer inoperável ou doenças semelhantes. Se entre o narcótico e a abreviação da vida não existe nenhum nexo causal direto, e se, ao contrário, a administração de narcóticos ocasiona dois efeitos distintos: de um lado aliviando as dores e de outro abreviando a vida, serão lícitos. Precisamos, porém, verificar se entre os dois efeitos há uma proporção razoável, e se as vantagens de um compensam as desvantagens do outro. Precisamos, também, primeiramente verificar se o estado atual da ciência não permite obter o mesmo resultado com o uso de outros meios, não podendo ultrapassar, no uso dos narcóticos, os limites do que for estritamente necessário.

Sendo assim, o Papa Pio XII repudia a morte assistida, mas garante anuência do uso do avanço da tecnologia se este constitui melhorias para a saúde, principalmente para o alívio das dores do paciente, respeitando o limite necessário do uso de analgésicos que atuam para cessar a dor e que não obstruam o paciente de suas faculdades mentais. É, ainda, reconhecível que a igreja tem grande influência sobre seus fiéis, usando a bíblia como grande transmissor dos ensinamentos proféticos, até porque a religião é um conjunto de crenças e visões de mundo que perpassam para seus seguidores. Todos esses ensinamentos e a posição moral da igreja ocasionam uma persuasão pública do que é correto e justo e do que Deus aprova ou deixa de aprovar. Isto posto, a igreja é, além de todas as suas demais características, uma espécie de condutora do homem na sociedade. Conforme afirmou Jürgen Habermas ${ }^{29}$ em sua obra "A inclusão do outro":

As tentativas de explicação do "ponto de vista moral" lembram que os mandamentos morais, após o desmoronamento de uma visão de mundo "católica", obrigatória para todos, e com a passagem para as sociedades de cosmovisão pluralista, não mais podem ser justificados publicamente segundo um ponto de vista divino transcendente. Segundo esse ponto de vista, para além do mundo, era possível objetivar o mundo como um todo. O "ponto de vista moral" deve reconstruir essa perspectiva intramundialmente, quer dizer, deve recuperá-la dentro dos limites de nosso mundo compartilhado intersubjetivamente, sem perder a possibilidade do distanciamento do mundo como um todo, nem a da universalidade de um olhar que abarca o mundo todo.

À vista disso, o ponto de vista moral sobre os fatos não pode mais ser embasado em um ponto de vista divino transcendente, porque este é estabelecido como um ponto de vista antigo e anacrônico, e é crucial pensar os fatos de forma plural, incluindo a bioética. Pluralidade é diversidade, e a pluralidade entende-se melhor e mais justa do que a singularidade, pois é reconhecível que a sociedade é repleta de multiplicidade, então parece mais justo aceitar a autonomia do outro que não interfere na sua do que a reprimir. Por sua vez, de acordo com Volnei Garrafa ${ }^{30}$ :

O papel da Bioética não é a obrigatória resolução de conflitos, mesmo porque existem conflitos (como o aborto, por exemplo) que simplesmente não são solucionáveis sob a ótica de uma ética que se queira universal. Entre indivíduos de moralidades diversas,

29 HABERMAS, J. A inclusão do outro. São Paulo: Loyola, 2002.

30 GARRAFA, V; COSTA, S. I. F. A bioética no século XXI. Brasília: UnB, 2000. 
o importante não é a resolução obrigatória para os conflitos, mas a capacidade de se desenvolver uma tolerância respeitosa que nos permita conviver pacificamente com moralidades diferentes da nossa, em um mundo secularizado e complexo que deixou há muito tempo de ser canônico.

Por conseguinte, Garrafa reconhece que no século XXI, ou até mesmo antes, o mundo já não corresponde mais a um lugar de regras e morais cânones. A igreja, por sua vez, parece manter a sua rejeição à morte assistida, tutelando, a partir de seus ensinamentos bíblicos, a assimilação de que Deus é soberano sobre a vida de cada pessoa, e enxergando a morte não como uma possível "morte boa ou digna", mas como uma obstrução da vida que Deus criou. No entanto, o Vaticano concedeu a Declaração sobre a eutanásia da sagrada congregação para a doutrina da fé $\mathrm{e}^{31}$, em 05 de Maio de 1980:

Não se pode, portanto, impor a ninguém a obrigação de recorrer a uma técnica que, embora já em uso, ainda não está isenta de perigos ou é demasiadamente onerosa. [...]. $\mathrm{Na}$ iminência de uma morte inevitável, apesar dos meios usados, é lícito de forma consciente tomar a decisão de renunciar ao tratamento que daria somente um prolongamento precário e penoso à vida, sem contudo interromper os cuidados normais devidos ao doente em casos semelhantes.

Logo, a posição da Igreja Católica vai de encontro com a ortotanásia, pois considera lícito e viável o alívio da dor e do sofrimento do paciente, tendo o médico a obrigação de tratar do paciente e respeitar a sua dignidade como pessoa humana. Ainda, considera justo que o paciente opte por cessar tratamentos penosos que prolonguem a sua vida, que não há mais perspectiva de melhora, por meio dos avanços tecnológicos. A Igreja Católica parece, então, distanciar-se da prática da distanásia e se aproximar da ortotanásia, esta, por sua vez, possuindo como maior característica a morte natural. Portanto, o pensamento canônico entende que a partir do momento que uma pessoa escolhe morrer, não de forma natural, mas, por meio da morte assistida, ela está agindo com complexo de Deus, ou seja, tomando uma decisão que só Deus poderia tomar e fazer acontecer. Esta é uma posição moral que colide com a posição do pluralismo ideológico, portanto, se essas diferentes posições forem pensadas sob o amparo da autonomia da vontade, percebe-se que há um prevalecimento - não uma interferência - da autonomia cristã sobre a autonomia individual de cada pessoa. Esse prevalecimento acontece porque o ponto de vista moral anuente e lícito é o ponto de vista cristão que repudia a morte assistida, porém ele não parece justo. $\mathrm{O}$ ponto de vista do pluralismo ideológico parece mais razoável porque ele opta pela diversidade, esta não coage ou reprime ninguém a ter condutas que deveriam ou não ser tomadas, ela apenas concede ao indivíduo a liberdade ou autonomia de escolha para tomar uma decisão sobre si próprio - que não interferirá na esfera de

31 Declaração sobre a eutanásia da sagrada congregação para a doutrina da fé. Vatican. Disponível em <http://www.vatican.va/roman_curia/congregations/cfaith/documents/rc_con_cfaith_doc_19800505_euthana sia_po.html>. Acesso em 10 agosto de 2019. 
autodeterminação de outrem - ou, simplesmente, não tomá-la. O pluralismo, então, oferece a possibilidade de escolher ou não escolher, enquanto o ponto de vista canônico oferece a possibilidade apenas de não escolher - "não deve abortar", "não deve recorrer à morte assistida" -. Não parece mais justo e razoável que os pacientes que anseiam por ter autonomia de escolha para optar pela eutanásia possa fazê-lo, e as pessoas que repudiam a morte assistida não precisem fazê-la? É exatamente nesta indagação que se encontra o ponto de vista do pluralismo ideológico, porém a moral cristã nos mostra que ninguém deve optar por praticar a eutanásia e esta é a realidade brasileira -, mesmo que haja aqueles que queiram.

\section{PERSPECTIVA FAMILIAR}

O entrelaçamento da morte assistida com a dinâmica familiar é provável em demasia de acontecer. O paciente que demonstra vontade de programar sua morte, para cessar seus sofrimentos e dores de uma vida sem perspectiva de melhoras, quase sempre terá sua vontade combatida pelos familiares. A justificativa mais acurada é que ninguém quer privar-se de um ente querido, afinal, já é doloroso perdê-lo por morte natural, então por morte antecipada é subversivo.

É quase impossível que a análise da conduta dos familiares não seja mais subjetiva, volvendo para questões psíquicas. As emoções e os sentimentos contrapõem a possibilidade da prática da eutanásia em um ente querido, mas o crucial é observar quais os sentimentos que se dispõem neste momento - o egoísmo ou a compaixão?

Testemunhar uma pessoa querida padecer sem perspectiva de vida e sofrer em dores insuportáveis e, ainda assim, repudiar qualquer vontade dessa pessoa de obter uma morte assistida parece mais com egoísmo do que compaixão, pois há uma necessidade própria da família de manter essa pessoa enferma por perto e de que esse enfermo tenha o direito de lutar contra a morte, mesmo que ela esteja agonizando em dores insurgentes. Logo, com o desespero e o repúdio dos familiares à morte assistida, o paciente acaba sentindo-se ingrato à família por pensar em programar a própria morte e, desta forma, desistido de fazê-la e optando por continuar a sofrer. Por sua vez, a compaixão fornece ao ser humano uma visão mais empática da dor do outro e a humildade de poder compreender a vontade do outrem.

Outrossim, a eutanásia involuntária é uma questão mais pertinente na perspectiva familiar. É crucial pensar sobre os riscos de eutanásia involuntária, na qual não há escolha do paciente ou sua anuência, pois, este, encontra-se inconsciente, mas, sim, a consideração da família em admitir a terminalidade da vida do enfermo. Logo, nesta última possibilidade, há 
uma transcendência da autonomia da vontade do paciente que se estende às considerações familiares. De acordo com Pessini ${ }^{32}$ :

dado o sofrimento emocional da família e os pesados custos sociais e econômicos de manter uma "coleção residual de sistemas de órgãos do corpo", o médico deve estar pronto para assistir a família do paciente ou o representante na decisão do que é melhor para o paciente.

No entanto, apenas o próprio paciente saberia o que é melhor para ele, porém, a eutanásia involuntária é ou pode vir a ser instrumento de pacientes em estado vegetativo, isto posto, a autonomia do paciente é impossível. Uma boa comparação é com o ato de doação de órgãos no Brasil. Para ser um doador de órgãos não basta apenas que a pessoa declare seu desejo de ser um doador, porque, posteriormente, a doação só poderá ser realizada por intermédio de autorização prévia da família. Sendo assim, após a morte, mesmo que o falecido tenha demonstrado em vida seu desejo de doar seus órgãos, ainda assim, a família pode optar por não o fazer.

Portanto, assim como na doação de órgãos, é a família que concede a autorização final na eutanásia involuntária. Logo, a autonomia da vontade do indivíduo é inexistente, pois a única vontade que prevalece é a da família, o que é arriscado, embora que mesmo sendo família, continua sendo um outro alguém decidindo sobre a morte do enfermo, quando essa decisão deveria ser deliberada apenas por ele mesmo.

\section{CONCLUSÃO}

Diante do trabalho exposto, a autonomia da vontade tem se mostrado como o espírito da dignidade da pessoa humana, sendo inerente a ela. Isto posto, como a dignidade da pessoa humana concede o direito à vida, a autonomia da vontade em sentido da dignidade da pessoa humana deveria poder deliberar, também, pelo direito à morte digna. No entanto, a morte programada para cessar sofrimentos agonizantes de uma vida que não tem perspectiva de melhoras, pode causar sofrimentos emocionais aos familiares do enfermo que deseja passar pelo procedimento de morte assistida, e é neste sentido que se torna crucial o acolhimento de um genuíno ato de compaixão por parte dos familiares. Portanto, diante de uma existência extenuante, deve haver um resguardo de uma empatia pelas dores alheias sofridas e o respeito pela autonomia da vontade de cada indivíduo do Estado Democrático de Direito.

32 PESSINI, L. Distanásia: até quando prolongar a vida? São Paulo: Loyola, 2001. 


\section{REFERÊNCIAS}

ASÚA, L. J. Liberdade de amar e direito a morrer. Belo Horizonte: Mandamentos, 2003.

AUGUSTINE, ST. The Early Church Fathers and Other Works. Scotland: Wm. B. Eerdmans Pub. Co., 1867.

BARROSO, L. R.; MARTEL, L. C. V. A morte como ela é: dignidade e autonomia individual no final da vida. In: GOZZO, Débora; LIGIERA, Wilson Ricardo. Bioética e Direitos Fundamentais (Orgs.). São Paulo: Saraiva, 2012.

BRASIL. Código Penal Brasileiro. São Paulo: Rideel, 2019.

Constituição Federal. Disponível em

<http://www.planalto.gov.br/ccivil03/constituicao/constituicao.htm >. Acesso em 03/07/2019.

Instituto Brasileiro de Geografia e Estatística. Disponível em

<https://www.ibge.gov.br/estatisticas/sociais/trabalho/9662-censo-demografico-

2010.html?edicao=9749\&t=destaques $>$. Acesso em 03/07/2019.

Exposição de motivos da parte especial do código penal. Disponível em

<http://honoriscausa.weebly.com/uploads/1/7/4/2/17427811/exmecp_parte_especial.pdf $>$.

Acesso em 10/08/2019.

Christians remain world's largest religious group, but they are declining in Europe. Pew

Research Center. Disponível em <https://www.pewresearch.org/fact-

tank/2017/04/05/christians-remain-worlds-largest-religious-group-but-they-are-declining-in-

europe/> Acesso em 03/07/2019.

Declaração sobre a eutanásia da sagrada congregação para a doutrina da fé. Vatican.

Disponível em

<http://www.vatican.va/roman_curia/congregations/cfaith/documents/rc_con_cfaith_doc_198 00505_euthanasia_po.html> Acesso em 10 agosto de 2019.

DINIZ, M. H. O estado atual do biodireito. São Paulo: Saraiva, 2001.

Discurso del Santo Padre Pío XIII sobre las implicaciones religiosas y morales de la analgesia. Vatican. Disponível em <http://w2.vatican.va/content/pius-

xii/es/speeches/1957/documents/hf_p-xii_spe_19570224_anestesiologia.html>. Acesso em 03/08/2019.

GARRAFA, V; COSTA, S. I. F. A bioética no século XXI. Brasília: UnB, 2000.

GRECO, L. Posse de drogas, privacidade, autonomia: reflexões a partir da decisão do Tribunal Constitucional argentino sobre a inconstitucionalidade do tipo penal de posse de drogas com a finalidade de próprio consumo. Revista Brasileira de Ciências Criminais. São Paulo, v. XVIII, n. 87, nov./dez. 2010.

HABERMAS, J. A inclusão do outro. São Paulo: Loyola, 2002.

KANT, I. Fundamentação da metafísica dos costumes. In: Textos selecionados. São Paulo: Abril, 1994.

KANT, I. A metafísica dos costumes. São Paulo: EDIPRO, 2003.

KUNDERA, M. A insustentável leveza do ser. ed. 39. Rio de Janeiro: Nova Fronteira, 1985, p.26. 
MONTAIGNE, M. De como filosofar é aprender a morrer. vol. 1. São Paulo: Abril Cultural, 2000.

NEUKAMP, F. Zum. Problem der Euthanasie. Der Gerichtssaal, 109:403, 1937.

NINO, C. S. Ética y derechos humanos: un ensayo de fundamentación. Buenos Aires: Editorial Astrea de Alfredo y Ricardo DePalma, 2007.

OLIVEIRA, F. Engenharia genética: o sétimo dia da criação. ed. 3. São Paulo: Moderna, 1996.

PESSINI, L. Distanásia: até quando prolongar a vida? São Paulo: Loyola, 2001.

REIS, M. M. Teoria dos direitos fundamentais. $2^{\text {a }}$ ed. Rio de Janeiro: Renovar, 2009.

Resolução CFM No 1.805/2006. Conselho Federal de Medicina. Disponível em <http://www.portalmedico.org.br/resolucoes/cfm/2006/1805_2006.htm>. Acesso em 03/07/2019.

Resolução CFM n $n^{\circ}$ 1.995/2012. Conselho Federal de Medicina.. Disponível em <http://www.portalmedico.org.br/resolucoes/CFM/2012/1995_2012.pdf >. Acesso em 03/07/2019.

SALGADO, J. C. A idéia de justiça em Kant: seu fundamento na liberdade e na igualdade. Belo Horizonte: UFMG, 1986.

SARTRE, Jean-Paul. L'être et le néant: essai d'ontologie phénoménologique. France: Gallimard, 2001.

VIEIRA, T. R. Bioética e direito. São Paulo: Jurídica Brasileira, 1999, p. 90. 